\title{
Self-Reported Mental Health and Acculturation Stress Among Foreign-Born and U.S.-Born Latinos in Immokalee, Florida: A Pilot Study
}

\author{
Payal Kahar, $\mathrm{PhD}$ \\ Florida Gulf Coast University, Fort Myers, Florida, United States \\ (iD) https://orcid.org/0000-0002-3864-2100 \\ Lirio K. Negroni, PhD \\ Florida Gulf Coast University, Fort Myers, Florida, United States
}

Contact: pkahar@fgcu.edu

\section{Abstract}

The population of Immokalee in Southwest Florida is 75\% Latinos, with nearly half being foreign-born. Several documented stressors contribute to poor mental health among Latinos. However, little is known about Latinos' mental health in this region. This study sought to assess self-rated mental health (SRMH) and acculturation stress (AS) and predict SRMH based on stress from life events, AS, sociodemographic characteristics, and social support among U.S.-born and foreign-born Latinos. Face-to-face interviews and assisted self-administered surveys were used to collect information among 158 Latinos on sociodemographic characteristics, AS, major life events that caused stress, social support, and SRMH. AS was elicited by asking three questions (Cronbach's $\alpha=.84$ ), total stress level was determined by 10 major life events, and social support was elicited by 14 questions (Cronbach's $\alpha=.76$ ). Results indicated that foreign-born Latinos 36-75 years old, with minimal social support, U.S.-born Latinos with lower educational levels, minimal social support, and high-moderate stress levels reported statistically significant low SRMH. AS was significantly higher among foreign-born 36- to 75-year-olds, with lower educational levels, minimal social support, who preferred the Spanish language and lived $\leq 15$ years in the United States. Linear regression analysis showed social support, educational levels, and life stressors to be significant predictors of SRMH among U.S.-born Latinos, whereas social support was a significant predictor in foreign-born Latinos.

Keywords: foreign-born, acculturative stress (AS), self-rated mental health (SRMH), Southwest Florida

Date Submitted: September 3, 2019 | Date Published: March 26, 2020

\section{Recommended Citation}

Kahar, P., \& Negroni, L. K. (2020). Self-reported mental health and acculturation stress among foreign-born and U.S.born latinos in Immokalee, Florida: A pilot study. Journal of Social, Behavioral, and Health Sciences, 14, 21-36. https://doi.org/10.5590/JSBHS.2020.14.1.03 
Kahar \& Negroni, 2020

\section{Introduction}

Latinos are the largest ethnic group constituting $18 \%$ of the United States population in 2017 with a projected population increase to $28 \%$ in 2060 (Radford \& Noe-Bustamante, 2019; U.S. Census Bureau, 2018). With an overall increase in the nation's Latino population, the foreign-born Latino population has also increased from $28.3 \%$ in 1980 to $34.4 \%$ in 2015 (Flores et al., 2017). With nearly $75 \%$ Latino population and 50\% foreignborn, Immokalee, a territory within Collier County located in Southwest Florida, is home to several migrant farmworkers and immigrant families (U.S. Census Bureau, n.d.).

With stricter immigration laws and the devastation brought by Hurricane Irma in 2017, Immokalee residents were at an increased risk for both physical and mental health problems (Kahar \& Negroni, 2019). In addition to recent exacerbations in health issues stemming from the natural disaster, the nature of work the immigrant population is engaged in, nonurban residence, everyday stressors, and the pressure to acculturate contribute to the health issues among the residents (Kahar \& Negroni, 2019). Past community assessments by the Florida Department of Health, Health Planning Council of Southwest Florida emphasized the area of mental health among Collier County residents; however, the diversity of Collier County and the demographic makeup of Immokalee limited the generalizations of the collected data (Florida Department of Health in Collier County, 2016). Given the increasing number of Latinos and the paucity of data specific to mental health on foreignborn and U.S.-born Latinos in Southwest Florida, more research is warranted to better understand the population's health and direct public health policies.

Although the experience of resettling in a new country may be associated with increased mental health risks, immigrant Latinos, especially Mexican immigrants, have a significantly lower risk for depressive disorders, anxiety, substance abuse, and psychotic disorders than U.S.-born Latinos (Alegría et al., 2008; Breslau et al., 2007). The "acculturation hypothesis" suggests first-generation immigrants have an initial health advantage including better mental health status than Latinos born in the United States and more acculturated Latinos. (Escarce et al., 2006).

Acculturation characterizes the time spent in the United States by foreign-born individuals wherein immigrants develop connections and identification with another culture. In this process, they may adopt less constructive behaviors of the dominant U.S. society and change some protective aspects of their culture such as their sense of identity and social connections. The process of cultural change, erosion, and adaptation may become a stressor eliciting various physiological and emotional reactions among immigrant populations (Castañeda et al., 2015; Finch et al., 2004; Scribner \& Dwyer, 1989; Scribner, 1996).

Acculturation stress (AS) refers to negative experiences (emotional tensions) resulting from immigrating and encountering a new culture or cultures (Berry et al., 1987). Studies show AS to be associated with depression, suicidal ideation, substance abuse and comorbidity (Finch \& Vega, 2003; Kiang et al., 2010). Even though immigrants have variations in acculturation experiences, risk factors for mental health such as discrimination, financial hardship, and difficulty accessing basic services because of language barriers stemming from immigration experiences remain common among the group (Alegría et al., 2017; Kim et al., 2010; Wohler \& Dantas, 2017).

Although immigration experiences may affect mental health among foreign-born Latinos, their strong social support systems act as buffers to safeguard their good mental health and in some instances, even better mental health and AS. Social support takes several forms: informational social support in terms of knowledge about salutary health behaviors; knowledge about access to health services; instrumental social support in terms of extended family members or friends to rely on in times of need; and emotional support in terms of providing empathy, understanding, and care (Cohen, 2004; Loue, 1998). Given that many immigrants fare 
well postmigration, instrumental support likely plays an important role in alleviating AS and generalized demands of everyday life (Kiang et al., 2010).

Stress arising from experiencing general problems, interpersonal conflicts, and uncontrollable events known as normative stress has been long associated with poor mental health (Gonzales et al., 2001). Considering both normative and acculturative stressors and separate one from the other is important to understand mental health of immigrants and target intervention strategies for effective coping (Castañeda et al., 2015; Finch et al., 2000; Finch \& Vega, 2003; Gil et al., 1994; Gonzales et al., 2001; Lee, 2014; Loue, 1998; Osypuk, 2013; Vega \& Rumbaut, 1991).

The definition of mental health includes emotional, psychological and social well-being. It affects a person's thoughts, feelings, actions, stress management, relationships, and decision making (Parekh, 2018). Mental health is a broad concept in Latino culture that can be interpreted to be loco or loca, meaning "crazy," or problemas de nervios or sufrir de los nervios, meaning "problems with the nerves," such as psychological distress, depression, or anxiety (Santos-Lozada, 2016). Sufrir de los nervios appears to be more acceptable and less stigmatized in the Latino community. Self-rated mental health (SRMH) is a valuable and reliable indicator of emotional well-being, and prior studies have found SRMH to be correlated with depression, psychological distress, and use of mental health services (Fleishman \& Zuvekas, 2007; Katz et al., 1997; Mawani \& Gilmour, 2010).

Demographic factors such as obatining low educational levels, being female, and being older (45 years and older) have also been linked with higher odds of reporting poor/fair SRMH in Latinos (Santos-Lozada, 2016). Latinos generally migrate to the United States with low levels of human capital, work in low-wage occupations, and live in poor communities. Studies have shown their relative disadvantaged economic position within the U.S. society to be linked with poor mental health as well (Portes \& Rumbaut, 2001; Williams et al., 2007; Williams et al., 2010).

Despite the growing body of evidence on self-rated health and SRMH, there has been no previous research on the immigration experiences and SRMH among Latinos in Southwest Florida. Therefore, the primary objective of the study was to determine the differences in SRMH and AS in foreign-born and U.S.-born Latinos. The second objective was to determine if factors such as life stressors, social support, AS, socioeconomic status, gender, age, and language preference affected SRMH.

\section{Method}

\section{Research Design and Procedure}

This was a cross-sectional study conducted from July to December 2017. The questionnaire consisted of questions in areas of (a) sociodemographics, (b) self-rated physical and mental health, (c) health behaviors and health care, and (d) health-related social and cultural factors. It was developed in English, translated into Spanish, and translated back into English by an experienced bilingual translator. The Spanish version of the questionnaire was pilot-tested with three Spanish-dominant Latinos and the English version by two Englishdominant Latinos. Community leaders and service providers, in addition to research assistants helped in the voluntary recruitment of participants through flyers and word-of-mouth. Research assistants collected data at various locations such as a social services agency, a church, local businesses and neighborhoods in Immokalee through interviewing Latinos face to face or assisting participants in filling out the survey. Face-to-face interviews were conducted by asking each question verbally and recording the participants' responses. For self-administered surveys, participants filled in the responses and clarification was provided when participants were unclear about a particular question. In addition, research assistants reviewed the responses to check for completion and accuracy. To avoid systematic and random errors in the two methods of data 
collection, research assistants underwent training and were oriented on how to paraphrase questions if participants wanted to better understand the questions. Research assistants did not note any special circumstances about the face-to-face interviews or the assisted self-interviews that might have affected the answers given. Most of the participants preferred face-to-face interviews over self-administered surveys.

\section{Participants}

Adults (18 years and older) who self-identified as Latinos living in Immokalee were eligible for the study. A total of 156 residents consented to participate.

\section{Measures}

\section{Demographics}

The study collected information on participants' gender, age, educational status, income level, country of birth/origin, full-time or part-time employment, religious affiliation, and language preference. Age was divided into two groups: $18-35$ years and 36-75 years. Years lived in Southwest Florida were categorized as 1-15 years and 16-75 years. Risks for mental health conditions increase with continued residence of 13 years and more (Vega et al., 2004).

\section{SRMH}

The participants were asked to rate their mental health from 1 (very poor) to 5 (very good). SRMH was defined as emotional well-being or bienestar emocional, referring to absence of mental health problems, or problema de los nervios such as depression, anxiety, and psychological distress.

\section{AS}

Three Likert-type questions measuring pressure to acculturate from the shortened version of MultiDimensional Acculturative Stress Inventory were included in the questionnaire (Castillo et al., 2015; Rodriguez et al., 2015). The shortened version of the questionnaires was validated and used in Latino population previously. The responses varied from strongly disagree $(-2)$ to strongly agree $(+2)$. A score of -6 denoted low AS while +6 indicated high AS. The Cronbach's alpha for this scale was 0.84 indicating good reliability.

\section{Stress Levels}

Ten life events eliciting stress levels were part of the Holmes and Rahe Stress Inventory (Holmes \& Rahe, 1967). Items such as moved to a different place, faced legal problems, had a child in trouble, arguments in the family, serious illness of family member, financial problems, death in the family, birth of child/grandchild, and trouble with close friends were not only commonly reported but were also perceived to be negative or undesirable for most people and had large a priori Life Change Unit scores (Dohrenwend et al., 1978; Dohrenwend, 2006; Holmes \& Rahe, 1967). The participants were asked to indicate whether they experienced any of the ten life events in the past 12 months and the level of stress caused by that particular event by choosing 3 (caused very much stress), 2 (caused some stress), or 1 (caused minimal stress). Scores of o-10 were categorized as minimal stress and scores 11-30 were categorized as moderate-high stress levels. The Cronbach's alpha for this scale was 0.76 .

\section{Social Support}

Social support was elicited by 14 statements adapted from the 19-item validated Medical Outcome Study survey (Sherbourne \& Stewart, 1991). Participants were asked about the frequency of the availability of the support that varied from o (never), 1 (few times), 2 (sometimes), 3 (most of the time), to 4 (all of the time). The total support was categorized into two categories: most to all the time (29-56) and sometimes to never (o-28). Cronbach's alpha was 0.95 indicating good reliability and convergent validity. 
Kahar \& Negroni, 2020

\section{Data Analysis}

Data collected were entered into an Excel sheet and then imported into SPSS Version 24. Descriptive statistics included gender, age, educational level, religion, monthly income, employment type, and language preference by whether they were U.S.-born or foreign-born. Sociodemographic data were missing on religion and income for 5 and 23 participants respectively (they chose not to answer). SRMH and AS data were missing for one participant. The analyses were limited to complete cases through listwise deletion of cases with missing information. A two-way analysis of variance was carried out to examine the differences in the means for SRMH and AS across sociodemographic variables and stress levels. Finally, linear regression was carried out to estimate the effect of demographic factors, life events, stress levels, and social support on SRMH among U.S.-born and foreign-born Latinos.

\section{Results}

Table 1 shows the frequency distribution of the various sociodemographic variables by foreign-born or U.S.born. There were more foreign-born men (63.6\%) and women $(64.4 \%)$ than U.S.-born men (36.4\%) and women (35.6\%). A larger number of Latinos between the ages 36-75 years were foreign-born (85\%), whereas in the age group of $18-35$ years, there were marginally larger numbers of U.S.-born (54.2\%) than foreign-born (45.8\%). A higher proportion of foreign-born participants had no formal education (94.4\%), less than high school education (88.1\%) or bachelor's degree (60\%) than U.S.-born, respectively. Most of the foreign-born participants were Catholic (72\%). A fewer number of participants (23 of 158) indicated they were non-Catholic and nearly $74 \%$ of those were U.S.-born. Approximately $68 \%$ of the foreign-born earned an average of $\$ 2,500$ and below, while individuals earning more than $\$ 2,500$ monthly were split equally between foreign-born and U.S.-born Latinos. A higher percentage of foreign-born were either employed full-time (61.3\%) or part-time (72.7\%). A greater percentage of U.S.-born Latinos preferred either English (82.7\%) or both English and Spanish (83.3\%) as compared to foreign-born Latinos, the majority of whom preferred Spanish (96.7\%).

Table 2 shows a two-way analysis of variance comparing the mean SRMH scores between foreign-born and U.S.-born Latinos across sociodemographic variables, stress, and social support levels. SRMH mean score was higher in the U.S.-born participants aged $18-35$ years $(M=4.05, S D=0.96)$ than the foreign-born group $(M$ $=3.87, S D=0.84)$. Latinos 36-75 years reported lower mean SRMH score, however, again in this age group, U.S.-born $(M=3.8, S D=1.32)$ had a slightly higher mean score than the foreign-born $(M=3.6, S D=0.77)$ and the difference in the mean scores was statistically significant $(F=5.04 ; p<.05)$. U.S.-born Latinos who had either an associate or bachelor's degree reported higher mean SRMH score $(M=4.56, S D=0.63, M=4.5$, $S D=0.57$, respectively) than foreign-born in those educational categories respectively. On the other hand, foreign-born who had some high school or less education had higher mean SRMH scores than U.S.-born with lower educational levels. The differences in the mean SRMH scores between U.S.-born and foreign-born across educational levels were found to be statistically significant $(F=5.14 ; p<.05)$. U.S.-born Latinos with minimal stress levels reported higher SRMH score $(M=4.16, S D=0.92)$ than foreign-born Latinos $(M=$ $3.72, S D=0.80$ ) with the same levels of stress. However, foreign-born participants with moderate-to-high levels of stress reported higher SRMH scores than U.S.-born Latinos $(M=3.5, S D=0.84$ versus. 3.2, $S D=$ 1.2). The differences in the mean SRMH across stress levels were statistically significant $(F=4.88 ; p<.05)$. Similarly, U.S.-born Latinos with social support most to all of the time $(M=4.3, S D=0.94)$ reported a slightly higher mean score than foreign-born $(M=4.1, S D=0.76)$. The difference was found to be statistically significant $(F=29.5 ; p<.05)$. 
Table 1. Demographics

\begin{tabular}{|c|c|c|}
\hline \multirow[b]{2}{*}{ Variable } & \multicolumn{2}{|c|}{$N(\%)$} \\
\hline & Foreign-born & U.S.-born \\
\hline \multicolumn{3}{|l|}{ Gender } \\
\hline Male & $42(63.6)$ & $24(36.4)$ \\
\hline Female & $58(64.4)$ & $32(35.6)$ \\
\hline \multicolumn{3}{|l|}{ Age } \\
\hline 18-35 years & $38(45.8)$ & $45(54.2)$ \\
\hline $36-75$ years & $62(84.9)$ & $11(15.1)$ \\
\hline \multicolumn{3}{|l|}{ Educational level } \\
\hline No formal education & $17(94.4)$ & $1(5.6)$ \\
\hline $\begin{array}{l}\text { Less than high school } \\
\text { education }\end{array}$ & $52(88.1)$ & $7(11.9)$ \\
\hline High school & $15(34.9)$ & $28(65.1)$ \\
\hline Associate & $10(38.5)$ & $16(61.5)$ \\
\hline Bachelor & $6(60.0)$ & $4(40.0)$ \\
\hline \multicolumn{3}{|l|}{ Religion } \\
\hline Catholic & $92(71.9)$ & $36(28.1)$ \\
\hline Non-Catholic & $6(26.1)$ & $17(73 \cdot 9)$ \\
\hline \multicolumn{3}{|l|}{ Monthly income } \\
\hline$\leq \$ 2,500$ & $80(67.8)$ & $38(32.2)$ \\
\hline$\geq \$ 2,501$ & $7(50.0)$ & $7(50.0)$ \\
\hline \multicolumn{3}{|l|}{ Employment type } \\
\hline Full-time & $46(61.3)$ & $29(38.7)$ \\
\hline Part-time & $32(72.7)$ & $12(27 \cdot 3)$ \\
\hline Unemployed & $22(59.5)$ & $15(40.5)$ \\
\hline \multicolumn{3}{|l|}{ Language preference } \\
\hline English & $9(17 \cdot 3)$ & $43(82.7)$ \\
\hline Spanish & $89(96.7)$ & $3(3.3)$ \\
\hline Both & $2(16.7)$ & $10(83.3)$ \\
\hline
\end{tabular}


Table 2. Self-Rated Mental Health (SRMH) by Sociodemographic Variables, Social Support, and Stress Levels

\begin{tabular}{|c|c|c|c|c|}
\hline \multirow[b]{2}{*}{ Variable } & \multicolumn{2}{|c|}{$N$} & \multicolumn{2}{|c|}{ SMRH, M (SD) } \\
\hline & Foreign-born & U.S.-born & Foreign-born & U.S.-born \\
\hline Gender & & & \multicolumn{2}{|c|}{$F=0.57 ; p=.45$} \\
\hline Male & 41 & 24 & $3.70(0.75)$ & $4.22(0.80)$ \\
\hline Female & 58 & 32 & $3.73(0.85)$ & $3.84(1.16)$ \\
\hline Age & & & \multicolumn{2}{|c|}{$F=5.04 ; p<.05$} \\
\hline 18-35 years & 38 & 44 & $3.87(0.84)$ & $4.05(0.96)$ \\
\hline $36-75$ years & 63 & 10 & $3.61(0.77)$ & $3.80(1.32)$ \\
\hline Educational level & & & \multicolumn{2}{|c|}{$F=5.14 ; p<.05$} \\
\hline No formal education & 17 & 1 & $3.52(0.94)$ & 3.0 \\
\hline $\begin{array}{l}\text { Less than high school } \\
\text { education }\end{array}$ & 52 & 6 & $3.56(0.7)$ & $3.17(1.83)$ \\
\hline High school & 16 & 27 & $4.25(0.57)$ & $3.81(0.88)$ \\
\hline Associate & 10 & 16 & $3.7(0.95)$ & $4.56(0.63)$ \\
\hline Bachelor & 6 & 4 & $4.2(1.16)$ & $4.5(0.57)$ \\
\hline Religion & & & \multicolumn{2}{|c|}{$F=0.18 ; p=.837$} \\
\hline Catholic & 92 & 35 & $3.71(0.81)$ & $4.03(0.89)$ \\
\hline Non-Catholic & 7 & 16 & $3.71(0.76)$ & $3.94(1.34)$ \\
\hline Monthly income & & & \multicolumn{2}{|c|}{$F=0.82 ; p=.443$} \\
\hline$\leq \$ 2,500$ & 81 & 36 & $3.74(0.80)$ & $3.81(1.06)$ \\
\hline$\geq \$ 2,501$ & 7 & 7 & $3.86(1.07)$ & $4.14(1.07)$ \\
\hline Employment type & & & \multicolumn{2}{|c|}{$F=0.59 ; p=.556$} \\
\hline Full-time & 48 & 27 & $3.80(0.80)$ & $4.07(0.96)$ \\
\hline Part-time & 32 & 12 & $3.53(0.76)$ & $4.25(0.75)$ \\
\hline Unemployed & 21 & 15 & $3.81(0.87)$ & $3.67(1.29)$ \\
\hline Language preference & & & \multicolumn{2}{|c|}{$F=1.84 ; p=.163$} \\
\hline English & 9 & 43 & $3.78(0.97)$ & $4.05(0.97)$ \\
\hline Spanish & 90 & 1 & $3.71(0.79)$ & 3.0 \\
\hline Both & 2 & 10 & $3.5(0.71)$ & $3.9(1.29)$ \\
\hline Total stress level & & & \multicolumn{2}{|c|}{$F=4.88 ; p<.05$} \\
\hline Minimal (scores $0-10$ ) & 95 & 45 & $3.72(0.80)$ & $4.16(0.92)$ \\
\hline Moderate-high (scores 11-30) & 6 & 9 & $3.5(0.84)$ & $3.2(1.2)$ \\
\hline Social support & & & \multicolumn{2}{|c|}{$F=29.5 ; p<.05$} \\
\hline Most to all of the time & 38 & 36 & $4.1(0.76)$ & $4.3(0.94)$ \\
\hline Sometimes to never & 59 & 19 & $3.5(0.70)$ & $3.5(0.96)$ \\
\hline Years lived in Southwest FL & & & \multicolumn{2}{|c|}{$F=0.80 ; p=.374$} \\
\hline $1-15$ & 46 & 6 & $3.8(0.81)$ & $4.2(0.8)$ \\
\hline $16-75$ & 52 & 47 & $3.6(0.7)$ & $4.0(1.1)$ \\
\hline
\end{tabular}


Table 3 shows a two-way analysis of variance comparing mean AS scores between foreign-born and U.S.-born across sociodemographic variables and social support levels. Mean AS score was lower among younger U.S.born $(M=-2.7, S D=3.0)$ than foreign-born $(M=0.7, S D=3.2)$ Latinos. Similarly, U.S.-born Latinos in age group 36-75 years reported lower AS $(M=-2.4, S D=4.3)$ than older foreign-born participants $(M=0.9, S D$ = 3.0). The mean AS difference was statistically significant between U.S.-born and foreign-born Latinos at different age groups $(F=7.6 ; p<.05)$. With the increase in educational levels for U.S.-born Latinos, the mean AS decreased. For foreign-born, AS also decreased with increase in educational levels, with the exception of foreign-born with a bachelor's degree reporting a higher AS mean score of $M=0.3, S D=3.27$. The difference in the mean AS scores across educational levels between foreign-born and U.S.-born Latinos was statistically significant $(F=10.8 ; p<.05)$. Participants whose language preference was either English or both had lower AS than U.S.-born Latinos and foreign-born who preferred Spanish only. The mean AS score was statistically significant between U.S.-born Latinos and foreign-born participants and their language preference $(F=34.1$; $p<.05)$. Both foreign-born and U.S.-born Latinos who had social support most to all the time had lower AS mean score ( $M=-0.2, S D=3.2$ and $M=-3.2, S D=3.1$, respectively) than those who had no or very little social support $(M=1.5, S D=2.7$ and $M=-1.5, S D=3.5)$. The difference in mean AS score was statistically significant between U.S.-born Latinos and foreign-born at varying levels of social support $(F=20.2 ; p<.05)$. Finally, foreign-born individuals who lived 16 years or more in the region had lower AS $(M=1.15, S D=3.1)$ than those who lived 15 years or less $(M=0.48, S D=2.98)$. Similarly, while U.S.-born Latinos had lower AS in the 1-15 years' residence category; with longer residence, their AS reduced $(M=-2.9, S D=3.27$ and $M=$ 1.0, $S D=3.63$, respectively) and these differences were statistically significant $(F=11.87 ; p<.05)$.

A multiple regression was carried out to predict mental health scores based on gender, educational levels, age, monthly income, AS, total stress, average life events, language preference, employment, and social support among U.S.-born and foreign-born Latinos. The regression models were a good fit for the data $(F(10)=4.6 ; p$ .000 ) with a $\mathrm{R}^{2}=.50$ and ( $\left.F(10)=3.0 ; p .003\right)$ with a $\mathrm{R}^{2}=.26$ for U.S.-born and foreign-born respectively. Educational level, average life events, and social support were significant predictors of SRMH scores for U.S.born Latinos while social support was the only significant predictor for foreign-born Latinos (Table 4). 
Table 3. Acculturation Stress (AS) by Sociodemographic Variables and Social Support

\begin{tabular}{|c|c|c|c|c|}
\hline \multirow[b]{2}{*}{ Variable } & \multicolumn{2}{|c|}{$N$} & \multicolumn{2}{|c|}{$A S, M(S D)$} \\
\hline & Foreign-born & U.S.-born & Foreign-born & U.S.-born \\
\hline Gender & & & \multicolumn{2}{|c|}{$F=2.34 ; p=.129$} \\
\hline Male & 42 & 24 & $1.23(3.0)$ & $-2.0(3.41)$ \\
\hline Female & 57 & 32 & $0.47(3.03)$ & $-3.09(3.12)$ \\
\hline Age & & & \multicolumn{2}{|c|}{$F=7.6 ; p<.05$} \\
\hline 18-35 years & 37 & 45 & $0.70(3.17)$ & $-2.69(3.0)$ \\
\hline $36-75$ years & 62 & 11 & $0.85(2.96)$ & $-2.36(4.34)$ \\
\hline Educational level & & & \multicolumn{2}{|c|}{$F=10.80 ; p<.05$} \\
\hline No formal education & 16 & 1 & $2.0(3.16)$ & 6.0 \\
\hline $\begin{array}{l}\text { Less than high school } \\
\text { education }\end{array}$ & 52 & 7 & $1.12(2.79)$ & $-1.14(4.49)$ \\
\hline High school & 15 & 28 & $0.13(3.18)$ & $-2.64(2.69)$ \\
\hline Associate & 10 & 16 & $-1.5(2.76)$ & $-3.44(3.09)$ \\
\hline Bachelor & 6 & 4 & $0.33(3.27)$ & $-4.0(2.44)$ \\
\hline Religion & & & \multicolumn{2}{|c|}{$F=1.1 ; p=.295$} \\
\hline Catholic & 91 & 36 & $0.78(3.14)$ & $-2.97(3.13)$ \\
\hline Non-Catholic & 6 & 17 & $1.16(1.17)$ & $-1.94(3.80)$ \\
\hline Monthly income & & & \multicolumn{2}{|c|}{$F=2.69 ; p=.071$} \\
\hline$\leq \$ 2,500$ & 79 & 38 & $0.99(2.98)$ & $-2.55(3.45)$ \\
\hline$\geq \$ 2,501$ & 7 & 7 & $-1.14(3.07)$ & $-3.71(1.97)$ \\
\hline Employment type & & & \multicolumn{2}{|c|}{$F=.47 ; p=.626$} \\
\hline Full-time & 46 & 29 & $1.20(2.97)$ & $-2.38(3.38)$ \\
\hline Part-time & 31 & 12 & $0.38(3.29)$ & $-2.83(3.35)$ \\
\hline Unemployed & 22 & 15 & $0.55(2.79)$ & $-2.93(3.15)$ \\
\hline Language preference & & & \multicolumn{2}{|c|}{$F=34.09 ; p<.05$} \\
\hline English & 9 & 43 & $-1.67(3.20)$ & $-3.0(2.82)$ \\
\hline Spanish & 88 & 3 & $1.17(2.81)$ & $2.0(4.58)$ \\
\hline Both & 2 & 10 & $-4.5(2.12)$ & $-2.4(3.94)$ \\
\hline Social support & & & \multicolumn{2}{|c|}{$F=20.2 ; p<.05$} \\
\hline Most to all of the time & 38 & 36 & $-0.21(3.24)$ & $-3.2(3.1)$ \\
\hline Sometimes to never & 60 & 19 & $1.5(2.71)$ & $-1.52(3.47)$ \\
\hline Years lived in Southwest FL & & & \multicolumn{2}{|c|}{$F=11.87 ; p<.05$} \\
\hline $1-15$ & 46 & 6 & $1.15(3.11)$ & $-1.0(3.63)$ \\
\hline $16-75$ & 52 & 47 & $0.48(2.98)$ & $-2.9(3.27)$ \\
\hline
\end{tabular}


Kahar \& Negroni, 2020

Table 4. Linear Regression Model for Self-Rated Mental Health as the Dependent Variable

\begin{tabular}{lcccccc}
\hline & \multicolumn{3}{c}{ Foreign-born } & \multicolumn{3}{c}{ U.S.-born } \\
\cline { 2 - 7 } Variable & $\boldsymbol{B}$ & $\boldsymbol{S E}(\boldsymbol{B})$ & $\boldsymbol{\beta}$ & $\boldsymbol{B}$ & $\boldsymbol{S E}(\boldsymbol{B})$ & $\boldsymbol{\beta}$ \\
\hline Age & -.23 & .18 & -.14 & .38 & .30 & .15 \\
Education & .16 & .08 & .21 & .40 & .14 & $.33^{*}$ \\
Gender & .06 & .16 & .04 & -.42 & .24 & -.21 \\
Monthly income & -.12 & .11 & -.11 & .07 & .14 & .05 \\
Employment & .01 & .10 & .01 & -.13 & .13 & -.11 \\
Total stress levels & .26 & .42 & .08 & .01 & .42 & .003 \\
Language & -.45 & .23 & -.23 & -.05 & .24 & -.02 \\
$\quad$ preference & & & & & .02 & .08 \\
Acculturation & .02 & .03 & .07 & .02 & .04 & $.32^{*}$ \\
$\quad$ stress & .33 & .08 & $.40^{*}$ & .42 & .18 & $-.41^{*}$ \\
Social support & .03 & .17 & -2.01 & .79 & \\
Average life events & -.62 & .48 & & .50 & & \\
$R^{2}$ & .23 & & & $4.61^{*}$ & & \\
$F$ & $3.0^{*}$ & & & & &
\end{tabular}

\section{Discussion}

To our knowledge, this is one of the first studies to assess and compare SRMH and AS among U.S.-born Latinos and foreign-born Latinos in Immokalee, Florida. Although community health assessments were conducted in Collier County throughout the years, the study's uniqueness consists its exclusive focus on acculturation and sociodemographic determinants of SRMH in Latino population and the defined locality of Immokalee in Collier County of Southwest Florida.

Latinos in this community perceived their mental health to be good. The overall mean SRMH score was $M=$ $3.8, S D=0.9$ with $65 \%$ of the participants reporting good to very good SRMH and the remaining $35 \%$ reporting fair to very poor SRMH. Average number of life events was less than one $(M=0.20, S D=.21)$ with low stress level $(M=4.4, S D=3.0)$. Pressure to acculturate (AS) was moderate with an overall average of $M=$ $-0.5, S D=3.5$. The findings suggest that the perception of emotional well-being among both foreign-born and U.S.-born Latinos was good despite a few everyday stressors and some pressure to acculturate. These findings can be seen from two perspectives. One perspective suggests that despite some stressors, there are factors that contributed to participants' positive perception of their emotional well-being. These factors merit further investigation. The other perspective pertains to the influence of mental health stigma on participants' responses. Societal stigma of mental health and possible discrimination participants might face could have affected participants' responses on SRMH. Responses might have been limited by the level of comfort and confianza (trust) about disclosing information related to their mental health (most interviews were face-toface).

AS was higher among foreign-born Latinos, which is consistent with previous studies (Finch et al., 2004; Kiang et al., 2010). The pressure to acculturate is real and stressful as it implies changes in lifestyle and learning a new language (Berry et al., 1987). The U.S.-born Latinos may have reported lower AS because they have not been exposed to the immigration experience except indirectly and vicariously through the lives of their parents and previous generations. The community of Immokalee has an established immigrant 
population where Spanish is widely spoken, and institutional supports in the form of churches, bilingual advocates, and schools make the transition less difficult (Griffith, 2008; Kiang et al., 2010).

Results illustrate some group differences among Latinos with SRMH and AS. Latinos in age group 36-75 years, with fewer years of education, experiencing moderate-high life stress levels and minimal social support reported lower SRMH scores than Latinos in age group 18-35 years, with higher educational attainment, experiencing low life stress levels and social support most to all-the-time respectively. In addition, foreignborn Latinos between the ages of 36-75 years, with low educational levels, minimal social support, a Spanish language preference, and have lived $\leq 15$ years in the United States experienced significant pressure to acculturate (AS).

Both foreign-born and U.S.-born Latinos with low educational attainment reported low SRMH and educational level was a significant predictor of SRMH among U.S.-born Latinos. Prior research has documented a causal relationship between higher levels of education and lower odds of reporting poor/fair self-rated health (Hu \& Hibel, 2013; Mirowsky \& Ross, 2008; Morales et al., 2002). Educational attainment can promote an individual's self-rated health with enhanced life and coping skills, and better life opportunities in terms of work and economic condition. Furthermore, education can encourage an individual to pay more attention to potential health issues and enable better access to resources (Hu \& Hibel, 2013). The results also indicated foreign-born Latinos experience lower AS with higher educational attainment. According to Bulut and Gayman (2016), assimilated Latinos (those with substantial ties to the U.S. culture and weakest ethnic identity) and bicultural Latinos (those with strong ties to both U.S. society and their ethnic heritage) reported higher educational levels than Latinos who were recent arrivals or separated from U.S. society (Bulut \& Gayman, 2016).

Latinos who experienced moderate-high life stress reported low SRMH and average life events were a significant predictor of SRMH among U.S.-born Latinos. Of the 10 life events that contributed to total stress levels, financial problems (39.5\%), moving to a new place (29.3\%), and death and illness of close relative and friend (23.4\%) were most commonly reported. The findings are consistent with previous studies that found normative stress to be associated with increased mental health issues (depression and anxiety) and comorbidity (Gonzales et al., 2001; Kiang et al., 2010). While the study attempted to distinguish between more general every-day demands from stressors tied to acculturation, three questions eliciting stress caused by legal problems, financial difficulties and moving to a new place may be associated with immigration experiences among foreign-born Latinos. Further analysis (not shown here) illustrated only legal problems to be reported slightly more among foreign-born Latinos.

Social support was a significant predictor of SRMH for both foreign-born and U.S.-born Latinos, a finding that is consistent with prior work (Kiang et al., 2010). Latinos report better mental and physical health when they perceive themselves supported (Cohen, 2004; Medina \& Negroni, 2014). Foreign-born Latinos form large social networks within their families and the community that negates external stressors on health through acceptance, respect, advice, information and other tangibles (Ruiz et al., 2016). In a study of Latinos, social connections in the form of family and friend support and neighborhood social cohesion were important for both self-rated mental and physical health (Mulvaney-Day et al., 2007). In addition, foreign-born Latinos reporting lower AS highlights the protective nature of social support in alleviating acculturative stress and successful resettlement, as documented in previous studies (Kiang et al., 2010; Ruiz et al., 2016)

Latinos in the younger age group (18-35 years) reported better SRMH and lower AS than Latinos in the 3675 years age group, findings that are consistent with a previous study (Cuellar et al., 2004). Younger participants, whether foreign-born or U.S.-born were more educated and given the protective effects of education on health and resettlement, younger Latinos had better SRMH and lower AS. Among younger foreign-born Latinos, more high school graduates migrating to the U.S. is associated with expanding higher education in Latin America and the Caribbean that increased enrollment from 21\% in 2000 to $40 \%$ in 2010 
(World Bank, 2017). On the other hand, study participants in the age group 36-75 years were mostly foreignborn with less than high school education reporting higher AS (57\%). Most studies looked at years lived in U.S. and its association with AS. However, in a study by Bulut and Gayman (2016), the mean age of Latino immigrants who were classified as "separated group of immigrants" (i.e., those having strong identity with their ethnic heritage, lengthy tenure in the United States and non-preference for English) was 55 years, much higher than mean ages in bicultural (37 years) or assimilate (37 years) classes (Bulut \& Gayman, 2016).

According to the Latino health paradox, foreign-born, especially recent immigrant Latinos have better health than U.S.-born Latinos. Latinos that are born and raised in U.S. and more acculturated present with poorer health profiles (Escarce et al., 2006). The Latino health paradox is not found to be universal and our study found U.S.-born Latinos to rate better SRMH than foreign-born Latinos. However, within foreign-born Latinos, recent immigrants with less than 15 years of residence in the U.S. reported better SRMH but higher AS than foreign-born with longer residence of 15 years or more, consistent with a previous study (Hamilton \& Hummer, 2011). The mean number of years for the foreign-born living in Southwest Florida was 17.5 years with the majority of them (83\%) from Mexico. It is our speculation that the myriad of conditions in agricultural industry where immigrant Latinos engage in as farmworkers result in less favorable mental health profiles among foreign-born Latinos (Grzywacz et al., 2006). However, on the other hand, Immokalee has been one of the region's traditional site for hosting and accommodating immigrants, especially farm workers. An established Spanish speaking community and existing community resources provide support to negate external stressors and provide resilience in the form of social support, which is evident in an overall good SRMH and moderate AS among foreign-born Latinos in Southwest Florida.

Our study had a few limitations. Nonrandom sampling of Latinos may limit generalizations to other analogous populations. This cross-sectional study does not draw any causal inferences between sociodemographic factors, social support, and SRMH or AS. Social desirability may have incorporated some information bias into the responses recorded, especially related to mental health. While we looked at various sociodemographic factors and their association with mental health, several individual-level and environmental factors affecting their mental health profiles were not considered in the study.

Despite the limitations, this study specifically contributes to the existing assessments in the underserved area of Immokalee, Florida and among Latinos in lesser-known areas of SRMH and AS. Latino populations in the U.S. are heterogeneous and highly varied resulting in different life experiences and health outcomes. Future studies should focus solely on migrant farmworkers in Immokalee and compare their mental health profiles with the general Latino immigrant population. Also, future studies should explore risk and protective factors such as religion, family cohesion, satisfaction with life, and family and community factors that could have a stronger influence on sense of well-being.

\section{Conclusions}

The present study portrays a Latino group with a relatively good perceived mental health. If the pressure of societal stigma and the lack of confianza did not bias responses, it becomes important to further study the factors that contribute to good SRMH despite some life stressors and pressure to acculturate.

The study indicated U.S.-born Latinos to report better SRMH than foreign-born Latinos in general and AS to be significantly high in certain sub-groups of foreign-born Latinos, particularly if they were older, had limited education and social support, preferred Spanish, and resided 15 years or less in the United States. Social support was the only significant predictor of SRMH among both foreign-born and U.S.-born Latinos emphasizing the importance of social support in both groups. Provision and expansion of existing resources to seek social support in community centers, churches, health centers and at social events may aid in alleviating AS and improving mental health. The study proposes that the Latino health paradox supported by previous studies is not always true for foreign-born and U.S.-born Latinos. 


\section{References}

Alegría, M., Álvarez, K., \& DiMarzio, K. (2017). Immigration and mental health. Current Epidemiology Reports, 4, 145-155. https://doi.org/10.1007/s40471-017-0111-2

Alegría, M., Canino, G., Shrout, P. E., Woo, M., Duan, N., Vila, D., .. Meng, X. (2008). Prevalence of mental illness in immigrant and non-immigrant U.S. Latino groups. American Journal of Psychiatry, 165(3), 359-369. https://doi.org/10.1176/appi.ajp.2007.07040704

Berry, J. W., Kim, U., Minde, T., \& Mok, D. (1987). Comparative studies of acculturative stress. International Migration Review, 21(3), 491. https://doi.org/10.2307/2546607

Breslau, J., Aguilar-Gaxiola, S., Borges, G., Kendler, K. S., Su, M., \& Kessler, R. C. (2007). Risk for psychiatric disorder among immigrants and their US-born descendants: Evidence from the national comorbidity survey replication. The Journal of Nervous and Mental Disease, 195(3), 189-195. https://doi.org/10.1097/01.nmd.0000243779.35541.c6

Bulut, E., \& Gayman, M. (2016). Acculturation and self-rated mental health among Latino and Asian immigrants in the United States: A latent class analysis. Journal of Immigrant and Minority Health, 18(4), 836-849. https://doi.org/10.1007/s10903-015-0258-1

Castañeda, H., Holmes, S. M., Madrigal, D. S., Young, M. D., Beyeler, N., \& Quesada, J. (2015). Immigration as a social determinant of health. Annual Review of Public Health, 36(1), 375-392. https://doi.org/10.1146/annurev-publhealth-032013-182419

Castillo, L. G., Cano, M. A., Yoon, M., Jung, E., Brown, E. J., Zamboanga, B. L., . . Whitbourne, S. K. (2015). Factor structure and factorial invariance of the multidimensional acculturative stress inventory. Psychological Assessment, 27(3), 915-924. https://doi.org/10.1037/pas0000095

Cohen, S. (2004). Social relationships and health. United States: American Psychological Association. https://doi.org/10.1037/0003-066X.59.8.676

Cuellar, I., Bastida, E., \& Braccio, S. M. (2004). Residency in the united states, subjective well-being, and depression in an older mexican-origin sample. Journal of Aging and Health, 16(4), 447-466. https://doi.org/10.1177/0898264304265764

Dohrenwend, B., Askenasy, A., Krasnoff, L., \& Dohrenwend, B. (1978). Exemplification of a method for scaling life events: The PERI life events scale. Journal of Health and Social Behavior, 19(2), 205-229. https://doi.org/10.2307/2136536

Dohrenwend, B. P. (2006). Inventorying stressful life events as risk factors for psychopathology. Psychological Bulletin, 132(3), 477-495. https://doi.org/10.1037/0033-2909.132.3.477

Escarce, J. J., Morales, L. S., \& Rumbaut, G. (2006). The health status and health behaviors of Hispanics. In M. Tienda \& F. Mitchell (Eds.), Hispanics and the future of America (pp. 362-409) National Academies Press. http://www.nap.edu/openbook.php?record id=11539\&page $=362$

Finch, B. K., Frank, R., \& Vega, W. A. (2004). Acculturation and acculturation stress: A social-epidemiological approach to Mexican migrant farmworkers' health. The International Migration Review, 38(1), 236262. https://doi.org/10.1111/j.1747-7379.2004.tbo0195.x

Finch, B. K., Kolody, B., \& Vega, W. A. (2000). Perceived discrimination and depression among Mexicanorigin adults in California. Journal of Health and Social Behavior, 41(3), 295-313. https://doi.org/10.2307/2676322

Finch, B. K., \& Vega, W. A. (2003). Acculturation stress, social support, and self-rated health among Latinos in California. Journal of Immigrant Health, 5(3), 109. 
Fleishman, J. A., \& Zuvekas, S. H. (2007). Global self-rated mental health: Associations with other mental health measures and with role functioning. Medical Care, 45(7), 602-609.

https://doi.org/10.1097/MLR.obo13e31803bb4bo

Flores, A., López, G., \& Radford, J. (2017). 2015, Hispanic population in the United States Statistical Potrait: Statistical potrait of Hispanics in the United States.

https://www.pewresearch.org/hispanic/2017/og/18/2015-statistical-information-on-hispanics-inunited-states-trend-data/

Florida Department of Health in Collier County. (2016). Collier County health assessment. http://collier.floridahealth.gov/programs-and-services/community-health-planning-andstatistics/public-health-information/ documents/communityhealthassessmentsum.pdf

Gil, A. G., Vega, W. A., \& Dimas, J. M. (1994). Acculturative stress and personal adjustment among Hispanic adolescent boys. Journal of Community Psychology, 22(1), 43-54. https://doi.org/AIDJCOP2290220106>3.0.CO;2-T

Gonzales, N. A., Tein, J., Sandler, I. N., \& Friedman, R. J. (2001). On the limits of coping. Journal of Adolescent Research, 16(4), 372-395. https://doi.org/10.1177/0743558401164005

Griffith, D. (2008). New midwesterners, new southerners: Immigration experiences in four rural American settings. In D.S. Massey (Ed.), New faces in new places: The changing geography of American immigration (pp. 179-210). Russell Sage Foundation. https://doi.org/10.7758/9781610443814.11

Grzywacz, J., Quandt, S., Early, J., Tapia, J., Graham, C., \& Arcury, T. (2006). Leaving family for work: Ambivalence and mental health among Mexican migrant farmworker men. Journal of Immigrant and Minority Health, 8(1), 85-97. https://doi.org/10.1007/s10903-006-6344-7

Hamilton, T. G., \& Hummer, R. A. (2011). Immigration and the health of U.S. black adults: Does country of origin matter? Social Science \& Medicine, 73(10), 1551-1560.

https://doi.org/10.1016/j.socscimed.2011.07.026

Holmes, T. H., \& Rahe, R. H. (1967). The social readjustment rating scale. Journal of Psychosomatic Research, 11(2), 213-218. https://doi.org/10.1016/0022-3999(67)90010-4

Hu, A., \& Hibel, J. (2013). Educational attainment and self-rated health in contemporary China: A surveybased study in 2010. The Social Science Journal, 5o(4), 674-680.

https://doi.org/10.1016/j.soscij.2013.04.013

Kahar, P., \& Negroni, L. K. (2019). Enhancing latinos/as' capacity for rebuilding and recovery: The Immokalee Latino health project. Unpublished manuscript.

Katz, S. J., Kessler, R. C., Frank, R. G., Leaf, P., Lin, E., \& Edlund, M. (1997). The use of outpatient mental health services in the United States and Ontario: The impact of mental morbidity and perceived need for care. American Journal of Public Health, 87(7), 1136-1143.

https://doi.org/10.2105/AJPH.87.7.1136

Kiang, L., Grzywacz, J. G., Marín, A. J., Arcury, T. A., \& Quandt, S. A. (2010). Mental health in immigrants from nontraditional receiving sites. Cultural Diversity and Ethnic Minority Psychology, 16(3), 386394. https://doi.org/10.1037/a0019907

Kim, G., Aguado Loi, C. X., Chiriboga, D. A., Jang, Y., Parmelee, P., \& Allen, R. S. (2010). Limited english proficiency as a barrier to mental health service use: A study of Latino and Asian immigrants with psychiatric disorders. Journal of Psychiatric Research, 45(1), 104-110.

https://doi.org/10.1016/j.jpsychires.2010.04.031 
Lee, W. (2014). Life course research: A review of factors contributing to health of immigrants in the United States. Journal of Scientific Research and Reports, 3(10), 1309-1318. https://doi.org/10.9734/JSRR/2014/7579

Loue, S. (1998). Handbook of immigrant health. Springer. https://doi.org/10.1007/978-1-4899-1936-6

Mawani, F. N., \& Gilmour, H. (2010). Validation of self-rated mental health. Health Reports, 21(3), 61. https://www.ncbi.nlm.nih.gov/pubmed/20973435

Medina, C. K., \& Negroni, L. K. (2014). LATIN@ELDERS: Securing healthy aging in spite of health and mental health disparities. In H. Vakalahi, G. Simpson \& N. Giunta (Eds.), The collective spirit of aging across cultures (pp. 65-85). Springer.

Mirowsky, J., \& Ross, C. E. (2008). Education and self-rated health. Research on Aging, 3o(1), 93-122. https://doi.org/10.1177/0164027507309649

Morales, L. S., Lara, M., Kington, R. S., Valdez, R. O., \& Escarce, J. J. (2002). Socioeconomic, cultural, and behavioral factors affecting hispanic health outcomes. Journal of Health Care for the Poor and Underserved, 13(4), 477. https://search.proquest.com/docview/220138266

Mulvaney-Day, N. E., Alegría, M., \& Sribney, W. (2007). Social cohesion, social support, and health among Latinos in the United States. Social Science \& Medicine, 64(2), 477-495. https://doi.org/10.1016/j.socscimed.2006.08.030

Osypuk, T. L. (2013). Invited commentary: Integrating a life-course perspective and social theory to advance research on residential segregation and health. American Journal of Epidemiology, 177(4), 310-315. https://doi.org/10.1093/aje/kws371

Parekh, R. (2018). What is mental illness? https://www.psychiatry.org/patients-families/what-is-mental$\underline{\text { illness }}$

Portes, A., \& Rumbaut, R. G. (2001). Legacies : The story of the immigrant second generation. University of California Press. https://ebookcentral.proquest.com/lib/[SITE ID]/detail.action?docID=227306

Radford, J., \& Noe-Bustamante, L. (2019). Immigrants in America: Key charts and facts. https://www.pewresearch.org/hispanic/2019/06/03/facts-on-u-s-immigrants/

Rodriguez, N., Flores, T., Flores, R. T., Myers, H. F., \& Vriesema, C. C. (2015). Validation of the multidimensional acculturative stress inventory on adolescents of Mexican origin. Psychological Assessment, 27(4), 1438-1451. https://doi.org/10.1037/pasooo0125

Ruiz, J. M., Hamann, H. A., Mehl, M. R., \& O’Connor, M. (2016). The Hispanic health paradox: From epidemiological phenomenon to contribution opportunities for psychological science. Group Processes \& Intergroup Relations, 19(4), 462-476. https://doi.org/10.1177/1368430216638540

Santos-Lozada, A. R. (2016). Self-rated mental health and race/ethnicity in the United States: Support for the epidemiological paradox. PeerJ, 4, e2508. https://doi.org/10.7717/peerj.2508

Scribner, R. (1996). Paradox as paradigm--the health outcomes of Mexican Americans. American Journal of Public Health, 86(3), 303-305. https://doi.org/10.2105/AJPH.86.3.303

Scribner, R., \& Dwyer, J. H. (1989). Acculturation and low birthweight among Latinos in the Hispanic HANES. American Journal of Public Health, 79(9), 1263-1267. https://doi.org/10.2105/AJPH.79.9.1263

Sherbourne, C. D., \& Stewart, A. L. (1991). The MOS social support survey. Social Science \& Medicine, 32(6), 705-714. https://doi.org/10.1016/0277-9536(91)90150-B

U.S. Census Bureau. (n.d.). American fact finder: Immokalee CPD, Florida [Interactive data source]. https://factfinder.census.gov/faces/tableservices/jsf/pages/productview.xhtml? src=CF 
U.S. Census Bureau. (2018). Hispanic population to reach 111 million by 2060. https://www.census.gov/library/visualizations/2018/comm/hispanic-projected-pop.html

Vega, W. A., \& Rumbaut, R. G. (1991). Ethnic minorities and mental health. Annual Review of Sociology, 17(1), 351-383. https://doi.org/10.1146/annurev.so.17.080191.002031

Vega, W., Sribney, W., Aguilar-Gaxiola, S., \& Kolody, B. (2004). 12-Month prevalence of DSM-III-R psychiatric disorders among Mexican Americans: Nativity, social assimilation, and age determinants. The Journal of Nervous and Mental Disease, 192(8), 532-541. https://doi.org/10.1097/01.nmd.0000135477.57357.b2

Williams, D. R., González, H. M., Neighbors, H., Nesse, R., Abelson, J. M., Sweetman, J., \& Jackson, J. S. (2007). Prevalence and distribution of major depressive disorder in African Americans, Caribbean Blacks, and non-Hispanic Whites: Results from the national survey of American life. Archives of General Psychiatry, 64(3), 305-315. https://doi.org/10.1001/archpsyc.64.3.305

Williams, D. R., Mohammed, S. A., Leavell, J., \& Collins, C. (2010). Race, socioeconomic status, and health: Complexities, ongoing challenges, and research opportunities. Annals of the New York Academy of Sciences, 1186(1), 69-101. https://doi.org/10.1111/j.1749-6632.2009.05339.x

Wohler, Y., \& Dantas, J. A. (2017). Barriers accessing mental health services among culturally and linguistically diverse (CALD) immigrant women in Australia: Policy implications. Journal of Immigrant and Minority Health, 19(3), 697-701. https://doi.org/10.1007/s10903-016-0402-6

World Bank. (2017). Higher education expanding in Latin America and the Caribbean, but falling short of potential. https://www.worldbank.org/en/news/press-release/2017/05/17/higher-educationexpanding-in-latin-america-and-the-caribbean-but-falling-short-of-potential

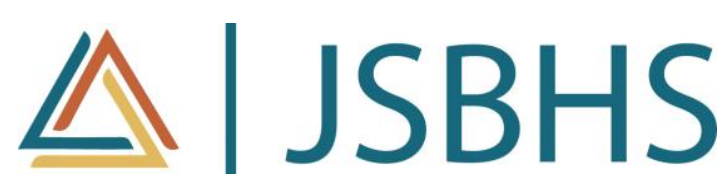

The Journal of Social, Behavioral, and Health Sciences (JSBHS), co-sponsored by the College of Health Sciences and the College of Social and Behavioral Sciences at Walden University, is a peer-reviewed, online, interdisciplinary journal focusing on theoretically-based research that addresses contemporary national and international issues. JSBHS articles include peer-reviewed research reports, brief resports, comprehensive literature reviews, books reviews, and student research. 